| ISSN(online): 2589-8698 || ISSN(print): 2589-868X ||

International Journal of Medical and Biomedical Studies

Available Online at www.ijmbs.info

Volume 2, Issue 5; September-October: 2018; Page No. 32-36

IJMBS

\title{
AQROECOLOGICAL SITUATION OF PROPOSALS, PROBLEMS AND SOLVING WAYS IN GARBAGE IN AZERBAIJAN
}

\section{Professor RAE. Aliev Z.H.}

Institute of Soil Science and Agrochemistry of ANAS, Baku

Article Info: Received 24 August 2018; Accepted 20 September. 2018

Cite this article as: Aliev Z.H., P. R. (2018). AQROECOLOGICAL SITUATION OF PROPOSALS, PROBLEMS AND SOLVING WAYS IN GARBAGE IN AZERBAIJAN. International Journal of Medical and Biomedical Studies, 2(5).

Address for Correspondence: Professor RAE. Aliev Z.H., Institute of Soil Science and Agrochemistry of ANAS, Baku

Source of support: Nil

\section{ABSTRACT:}

Afforestation and anthropogenic impacts of the primitive Torpag, grass cover and mainly pastures (degradation areas), degradation and degradation of forest ecosystems have led to considerable sharp reduction of the feed base in the Northern region. For a well-known purpose, Malik is a characteristic feature of Duran's relevance to the Agrarian Elmi, with a comprehensive approach to evaluating the agroeco-logical viewpoint of the existing and cultivated pasture production in the territory of the country, using Comprehensive Approach to Comprehensive Approach. Gobustan A detailed analysis of the five agro-ecological conditions of the winter pastures conducted by the district, the assessment of land and agrochemical groupings, etc. it is emphasized that it is necessary to carry out transport complex measures on improvement of complexes in wintered areas.

Key words: grazing lands, steppes, pastures, sophistication, measures of climate, agroecology, etc.

\section{INTRODUCTION:}

The fact that the Republic of Azerbaijan has been subjected to degradation of important agricultural land, including pasture and grassland productivity, does not meet the requirements for their use in the Northern region due to their fertility. On the other hand, the overburden load causes the low nutrient concentrate produced in the structure of the owl from the norm, the erosion and salinization of the soil as a result of their uncontrolled exploitation, and serious damage to the country's forest resources, water resources and the environment as a whole.

Development of agrarian sector in Azerbaijan to meet international requirements, efficient use, restoration, protection and productivity management of Roman Torpag resources is a requirement of the day, and fertility improvement should be carried out on agroecological basis. Along the agricultural sector in the region, as well as the main directions of agriculture in the Olan region, the purpose of creation of a sustainable and sustainable feed base in the region is to increase the agricultural production and to increase the production of feedstuffs.

From the point of view, the object of research suggests that severe degradation processes occurring in winter pastures in the Gobustan district of Szczecměstice have led to the occurrence of less productive Olan steam soils that threaten to overcome the sowing cycle. From this point of view, the relevance of the research work has been selected to meet the 
demands of the day, with the aim of increasing the productivity through the development of livestock in the country through more progressive methods, strengthening the protection of winter pastures and forests, increasing their use and preserving biodiversity.

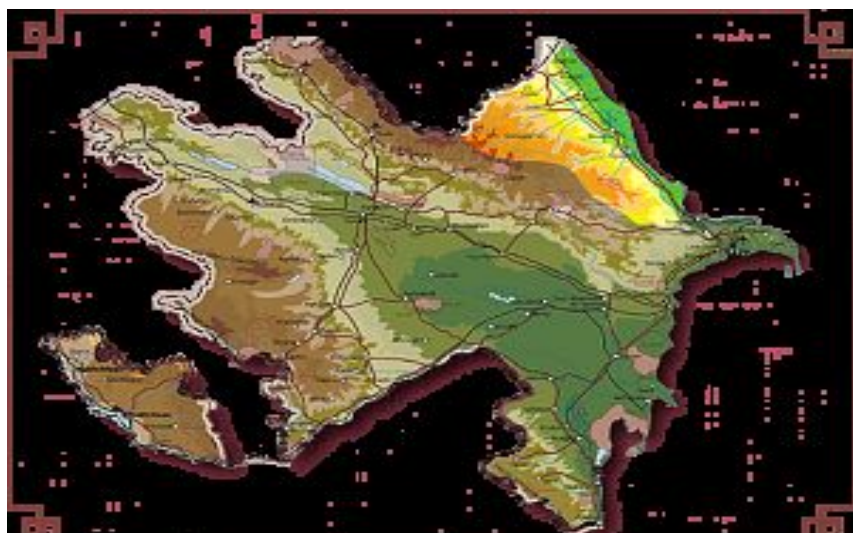

Figure 1:

Reasoning Research The main reason for irrational changes in agro-ecological potential is the pasture plowing, large-scale agro-melioration work, and large quantities of grazing landslides and powerful man-made effects. Thus, the problem is that the number of livestock increases by over a decade of pasture land degradation, and Kim's irreversible stages.

Herbaceous degradation leads to a reduction in biodiversity, fragmentation of the biosphere structure and the inability of the ecosystem to control itself. Here are some of the well-known part of the well-known program of well-being of the region, which is the basic habitat of the region and the animal kingdom Roman Olan, which has already helped to reduce the degradation of our pasture ecosystems, and the creation of a solid feed base, based on Malik, North.

Along with these, the research merchant has a problem with the actuality of the current market, meeting the requirements of the day, and is waiting for an Elmi-based solution, which has been studied by research.

Object of research: the main purpose of the research was to expand the pastures and grazing areas through the application of the results, using the latest research methods in the complex approach of agroecological features of the country's winter pastures in Gobustan region.

Object and methodology. The object of research was winter pastures located in the territory of Qobus, their main soil and vegetation. Land erosion surveys accompanying the practice of subsoil land are carried out in a wide range of research areas monitoring of hazardous graybrown soils of widespread erosion and their results were analyzed and agroecological assessment was carried out on the basis of commonly accepted methodology of academician GS Mammadov and B.H.Aliyev. Information on the erosion of the territory of the territory of the research site Region Nr. Total area (thousand hectares) Degree of erosion, including unspecified areas Erosion areas less than\% Hero $\mathrm{Ha} \% \mathrm{Ha} \%$ Poor Medium

Severity 123456789101112131

Gobustan 153.143 .523 .5143 .776 .524 .413 .0 33.517 .985 .845 .92

Shamakhi $161.262 .839 .894,860,238,323,3$ 21,6 13,7 34,9 22,2 3

Ismailli 194,4 89,8 41,3 127,5 58,7 55,8 25,7 28,3 $13,043.420 .04$

Aghsu 108.4 82.877.9 39.1 32.1 13.8 11.3 8.5 7.0 16.813 .8

For laboratory studies in selected field of practice, soil and plant samples taken and analyzed in the field of soil science research []. The main criterion for assessing land degradation is the obtaining of objective indicators affecting their genetic and agrochemical quality three: total humus, nitrogen, phosphorus, potassium, total absorbed bases: $0-20 \mathrm{~cm}$; 0 to $50 \mathrm{~cm}$; Reserve $0-100 \mathrm{~cm}$. Reserves of the selected agrochemical indicators ( $\mathrm{t} / \mathrm{ha}$ ) were calculated on the generally accepted formula for soil layers. During the research, the same plot of land, plant, landscape, geobotany maps and archive map fund of ANAS Institute of Soil Science and Agrochemistry were used []. 
The course of the study and the analysis of the results The total area of the land area of the cadastral region is 601.0 hectares, covering the flat and foothill areas of the district. The main types of landscapes are semi-desert and medium-sized dry steppes. Depending on the moisture degree (Md-0.10-0.15), the terrain is subdivided into zones.

The average annual amount of oils is 250-450 $\mathrm{mm}$. The district is completely heated. The total of temperatures above 100 is $4700-38000$.

The winter is soft here. The length of the vegetation period is 226-211 days. Mainly graybrown (brown), light gray-brown (chestnut), common gray-brown (chestnut), gray-gray, grass gray, light gray, primrose, grass-grass, forest grass, wet grass soils have spread.

Grass-brown, grass-gray and gray soil types are widely used in agriculture. However, in the pasture, the saline soils, clay and heavy-grained soils of these lands are widespread. In general, pasture pastures spread over cadastral district plains are 1193 thousand ha area, which is also distributed among the following administrative districts: Kim Ilhwa (Sahl Sahil) - 7,7 thousand ha; Agdash - 9.5 thousand hectares; Min Goychay 6.6 hectares; Укар-19,5 thousand hectares; Zardabski - 19.5 thousand hectares; Kurdemir 51.0 thousand hectares. Widespread soils throughout these regions are evaluated with the following points [4]: dark gray-brown-100mg; Gray brown-85; Light gray brown-73; dark grass90; Grass Lawn-71; gray grass-60; grass Boz-88; grass Gray brown-75; Subasar meadow-67; Boz63; open Boz-54; primary Boz-54; meadowforest-86; wet grass-58; Gray wax - 57 points. The Honey Ball Indicators refer to the tip of the ground and the type of landfill on the main Bonitzh postcard of the land area of academician QS Mammadov. []

Erosion, salinization, wormwood, aridation, desertification and so on. By taking into account the correlation coefficients, an open bin scale has been established, with the possibility to divide the land into quality groups. In the main pasture areas of the cadastral region of the cadastral region, saline, saline, Gilli, heavygrained, soils are widespread.

For our part, the results of desert-soil erosion research conducted by the Institute of Soil Science and Agrochemistry have been widespread in the area of erosion. .

Here, the erosion of the soil loses its structure, the soil becomes thicker, the carbonates grow, the amount of the absorbed bases is reduced, the mother goes to the surface, and the food is washed away. Significant changes have been made in the genetic layer of eroded soils.

The water-physic properties of erosioned soils increased considerably in heavily soaked soils: $1,15 \mathrm{~g} / \mathrm{cm} \mathrm{3} ; 2.62 \mathrm{~g} / \mathrm{cm} 3$, and the porosity was $55.20 \%$.

Quenching surveys, In rugged soils, steam figures $1.09 \mathrm{~g} / \mathrm{cm} 3 ; 2.57 \mathrm{~g} / \mathrm{cm} @$ 3; the porosity was $53.45 \%$. As a result, the humus, the total nitrogen content of the erosional soils was diminished in heavily soaked soils: $1.50 \%$ humus; Nitrogen $0,084 \%$-umumi. Steam figures in medium-sized soils 4, 29\%; And $0.225 \%$. The mechanical composition of these soils we have investigated is loamy soil : the amount of physical clay was $75.20 \%-63.60 \%$.

The erosion process in the area was strongly corroded by the structure-aggregate composition of the soil. In the heavily soiled soils, the size of 1 $\mathrm{mm}$ large aggregates is $52.68 \%$, and waterresistant aggregates are $21.20 \%$; these figures are $60.85 \%$ in moderately soiled soils; $33.80 \%$. The ability to absorb gray-brown soils has also declined as a result of the erosion process.

The amount of bases absorbed here has reached $17.5 \mathrm{mg} / \mathrm{sq} . / 13.0 \mathrm{mg} / \mathrm{eq}$, and $37.0 \mathrm{mg} / \mathrm{eqw}-$ $26 \mathrm{mg} / \mathrm{eV}$ in moderate wash. It should be noted that in the eroded soils, the amount of mesopharynphous phosphorus has dropped dramatically, and the nitrogen forms - ammonia, absorbed ammonia, and nitrates have been reduced in water. The analysis of the results of our research suggests that, by applying complex 
agro-meliorative measures, It is possible to increase the productivity of the territories.

Thus, various plants (phytomeliorants, clover, rye, raspberries, rye, etc.) have a positive impact on soil fertility, aggregation intensity of nutrients in soil, physical-chemical and agrophysical properties of soil. In many respects, it has been proven that the application of the fertilization system under the clover plant (with different norms and proportions) plays an exceptional role in improving soil fertility parameters, waterphysical properties and improving the food regimen of the cultivated plant, impacts the effect. []

According to the recommendations of Professor B.H.Aliyev, mineral fertilizers are allotted to the whole area in order to increase the eutectic effectiveness of fertilizers and to minimize the negative impact of their application on the environment, and thus direct localization to the Bitkin Kok system is more effective. The steam method, in turn, provides higher yields in fruit growing and viticulture.

The author believes that the use of fertilizers in the region using Suyu in the progressive region under the water scarcity is urgent, and increases the productivity of the foodstuff side by side, the product grows, along with its quality, improving the water-physic properties of the soils and increasing its fertility It is also believed that the bourse, which is of crucial importance in the development of the process of desirable erosion process, is one of the $\mathrm{HH}$ methods and the immediate measure is Kim's broad-minded application. It is possible to achieve a similar conclusion from the above mentioned Steam Recommendations They can improve the landscape of the winter pastures of the winter and cadastral region with erosion resistance. [1] .ELECTION: $40 \%$ of us have studied erosion, salinity, .

1.it is necessary to use perennial herbs to improve the fertility of these clay and heavy-clay soils. It is possible to improve the soil fertility by giving the mineral fertilizer under the grass, taking clover sage and mixed semen.

2. Herbaceous herbs are indispensable in the fight against erosion.

This grazing soil enriches with organic residues, while increasing roots are absorbed from the lower soils by removing the calcium element from the soil, improves the soil structure, improves water resistance, enriches soil erosion elements, and improves soil fertility.

3 Applying anti-erosion measures Thanks to the complex surface improvement carried out in the winter pasture lands, it is possible to improve the natural pastures and to obtain cheap and highquality feed, which is essential for the development of livestock breeding in the country and achieves a sustainable feed basin.

\section{LITERATUR}

1. B.H.Aliyev - Chemical Chemistry Analysis. Search 2th уч. Пособие для студентов ВУЗов. М .: Moscow. UNIT, 1970, 487 p.

2. HA - The role of perennial legumes and mineral fertilizers in the improvement of eroded soils. Protection of Torpag and Water Reserves. Baku-2008. № 3 .

3. A.M.Huseynov - erosion process and fight against it in the southern part of the Greater Caucasus (within the Azerbaijan Republic)measures. Baku, 2008, No.3.

4. B.Ş.Şakuri - Influence of mineral and microorganisms on biological processes on the brown and brown mountain-gray-brown (chestnut) soils of the Greater Caucasus. Land and water resources protection. Baku, 2008, № 3 .

5. Hasanov YD - Agrophysical properties of meliorated Azerbaijan and their productive capacity. Authors The doctrine Дисс ... Baku2006, 41 с. Косинский, В.В. Меркурьев, А.Г. Chupryakova. Formation of agglomerations of municipal formations: theoretical and practical aspects / PD- Tomsk: Izd vous Tom. flour, 2015. - $206 \mathrm{~h}$.

6. Mamedov G.Sh. - State Land Cadastre of Azerbaijan Republic: Right, Scientific and 
Prof. RAE Aliev Z.H., International Journal of Medical and Biomedical Studies (IJMBS)

Practical Problems. Baku. Elm, 2003, pp. 445, p. - Land. Baku-2005, 194 p. (Mamedov SZ, Jafarov AV, Svoystvo Prodhorodnyh of Baku, 2005, p. 194)

7. Metodic announcement of ukazania po posts kormovh ugodiy azerbaijani ussr business. Elm, 1978, 38 c.metodic analysis of ukasia populating options with the controlling kulturami. M; 1987, 197 c.

8. Movsumov Zr, Hasanova Af - Microfood reserve for increasing productivity of pasta. VOF t. V. Baku, 1995, p. 125-127. 